\title{
RELATO DE EXPERIÊNCIA SOBRE OS PROCESSOS EDUCATIVOS DE UMA OFICINA DE PIANO EM GRUPO PARA CRIANÇAS
}

\section{EXPERIENCE REPORT ABOUT EDUCATIONAL PROCESSES OF A GROUP PIANO WORKSHOP FOR CHILDREN}

\author{
Bianca Viana Monteiro da Silva \\ Universidade de São Paulo \\ bianca_vianam@hotmail.com \\ Simone Gorete Machado \\ Universidade de São Paulo \\ simonegorete@usp.br
}

\section{Resumo}

Este artigo é um relato de experiência sobre o projeto de extensão para crianças Oficina de Piano em Grupo, realizado por duas integrantes do grupo de pesquisa Música e Educação. As aulas foram oferecidas no Laboratório de Piano em Grupo, com duração de uma hora por semana, durante um semestre. A oficina teve por objetivo ofertar aulas de piano na modalidade de ensino coletivo para as crianças interessadas da comunidade, a fim de oferecer uma vivência em questões teóricas musicais atreladas à prática de tocar piano.

Palavras-chave: piano em grupo; educação musical; processos educativos; musicalização por meio do piano; habilidades funcionais.

\section{Abstract}

This article is an experience report about the outreach project for kids Oficina de Piano em Grupo, performed by two members of the 
research group Música e Educação. Classes were offered at the Group Piano Laboratory, one-hour a week for one semester. The workshop aimed to offer lessons on collective teaching mode for interested children of the community in order to offer an experience in musical theoretical questions linked to the practice of playing the piano.

Keywords: group piano; music education; educational processes; musicalization through the piano; functional skills.

\section{Lista de figuras}

Figura 1: Piano em grupo em formato de laboratório no LabPG.

Figura 2: Piano em grupo com dois pianos e oito crianças no LabPC.

\section{Introdução}

A promoção da Oficina de Piano em Grupo, um projeto de extensão, se deu pelo interesse em ensino coletivo de piano de duas integrantes do grupo de pesquisa Música e Educação: uma das autoras deste trabalho, Bianca Viana, e Giulia Salgado Coelho da Silva, aluna de graduação no campus de Ribeirão Preto da Universidade de São Paulo (USP/RP). O grupo de pesquisa é coordenado pela profa. dra. Simone Gorete Machado, docente da USP/RP. A oficina foi promovida pela Seção de Atividades Culturais: divisão de atendimento à comunidade, pela prefeitura da USP/RP. Foram ofertadas oito vagas para crianças de sete a nove anos, com encontros semanais de uma hora por semana durante um semestre do ano de 2017 - totalizando dez encontros. Os alunos interessados tiveram que fazer a inscrição por meio do site da Seção de Atividades Culturais, e as vagas ocupadas tiveram o critério de ser preenchidas por ordem de realização da inscrição. As aulas ocorreram no Laboratório de Piano em Grupo (LabPG) da profa. dra. Simone Gorete Machado, que também foi a coordenadora deste projeto. $\bigcirc$ laboratório conta com dez pianos, sendo oito pianos digitais para os estudantes, um piano digital para o professor e um piano de cauda para eventuais atividades. No decorrer da 
oficina, fizemos o uso, também, de fones de ouvido (um para cada aluno), projetor, computador e aparelho de som para proceder com a dinâmica dessa prática social. As aulas foram pensadas em dois eixos: em formato de laboratório e com um piano.

Oferecemos a oficina com o intuito de ofertar às crianças da comunidade a experiência da prática do piano e o conhecimento teórico musical. $\bigcirc$ objetivo era que elas vivenciassem alguns tópicos da educação musical por meio do piano. Foi um ambiente propício, no qual desenvolvemos várias habilidades funcionais, como: teoria musical, consciência corporal, leitura à primeira vista, memória, improvisação, musicalidade, criatividade, treinamento auditivo, entre outras. A elaboração das atividades foi feita de forma interdisciplinar, fazendo o uso da música vinculada às conteúdos escolares (como soma e subtração, divisão silábica, entre outras). Em todas as atividades desenvolvidas, tivemos o "lúdico" como dirigente, ou seja, toda atividade se constituiu, antes de em um "exercício", em um jogo ou brincadeira musical. As metodologias utilizadas foram de Irina Corin e Robert Pace.

\section{A prática humanizadora da Oficina de Piano em Grupo no LabPG e seus processos educativos}

Proporcionamos na oficina uma vivência de saberes teóricos musicais atrelados ao piano. Tivemos um compromisso social com o desenvolvimento de processos educativos que proporcionassem relações afetivas, sensibilidade auditiva, prática colaborativa, habilidades funcionais, entre outros. No decorrer da oficina, "buscamos meios para [...] identificar, compreender, descrever processos educativos que chegasse a observar" (SILVA, 2014, P. 21).

Fisher (2010) afirma que é muito eficaz introduzir conceitos musicais por meio do teclado em atividades de grupo. Ademais, Fisher (2010) afirma que os processos educativos promovidos na prática de ensino coletivo ao piano têm resultados importantes: faz estudantes aprenderem com seus pares e seu professor; propõe oportunidades ilimitadas de performance; cria variedade de repertório; encoraja o desenvolvimento de habilidades de escuta crítica, na medida em 
que os alunos ouvem seus colegas e fornecem comentários, após a performance; desafia os alunos a desenvolverem comunicação e habilidades sociais; encoraja a fazer transferências de conceitos e princípios; promove um ambiente dinâmico e um aprendizado motivacional; facilita a produtividade; se faz um excelente ambiente para proporcionar habilidades musicais funcionais; se constitui em um ambiente motivacional, no qual jogos criativos e exercícios podem ser usados para ensinar conceitos; tem o potencial de prender a atenção dos alunos por meio de atividades cativantes em uma prática coletiva; encoraja o desenvolvimento de senso rítmico por meio de atividades em grupo; se faz um ambiente natural para praticar música em conjunto (duetos, trios, quartetos, acompanhamento); desenvolve a interpretação musical conjunta; entre outros benefícios. Tais processos, ressaltados por Fisher (2010, p. 11, tradução nossa), foram “identificados, compreendidos e descritos" na realização da Oficina de Piano em Grupo para as crianças da comunidade.

\section{A modalidade de Piano em Grupo e seus formatos}

Dr. Robert Pace (1978, p. 2, tradução nossa), estudioso de piano em grupo e um dos precursores que, por meio de Marion Verhaalen, trouxe a modalidade ao Brasil, em 1973, pelo "Método Dr. Robert Pace" (MACHADO, 2016 , p. 138), afirma que há cinco modalidades de aula de piano:

- Ensino de piano individual: aulas tradicionais de piano, nas quais ocorre o ensino de um aluno por vez;

- master class: um encontro no qual a performance dos alunos

é analisada/criticada por um professor;

- instruções nas classes de piano: estudantes se encontram regularmente, sob a orientação de um instrutor, com o propósito de praticar determinado repertório. É uma prática realizada em conjunto, devido à dificuldade de cobrir a tarefa com muitos estudantes. Na instrução de "classe", não se espera que os alunos interajam ou critiquem-se. Em vez disso, eles praticam a peça de acordo com o que for solicitado pelo instrutor;

- experiência ao piano: teclado usado como um recurso tátil e audiovisual. Não são feitas tarefas fora da classe ou prática em casa, e nenhuma técnica ou repertório ao piano é experimentado. Essa modalidade oferece oportunidades para os alunos aprenderem os fundamentos da música abrangente em programas de música na escola; 
- piano em grupo: trata-se de uma situação de aprendizagem em que dois ou mais estudantes interagem sob a orientação de um professor em uma dinâmica mais complexa. Cada pessoa do grupo é constantemente envolvida, seja na performance, análise auditiva e visual, ou crítica construtiva de si e de seus pares. Cada membro sente uma responsabilidade para com os outros, e todos têm um senso de envolvimento pessoal.

A oficina realizada no LabPG teve a modalidade de piano em grupo, porém, com duas propostas: um piano para cada criança (em formato de laboratório) e dois pianos para todas as crianças (dois pianos disponibilizados para quatro crianças em cada um). Bianca Viana Monteiro da Silva ficou responsável pela aula em formato de laboratório, e Giulia Salgado Coelho da Silva ficou responsável pela aula em formato de poucos pianos para muitos alunos. Cada uma teve meia hora para lecionar, totalizando uma hora de oficina.

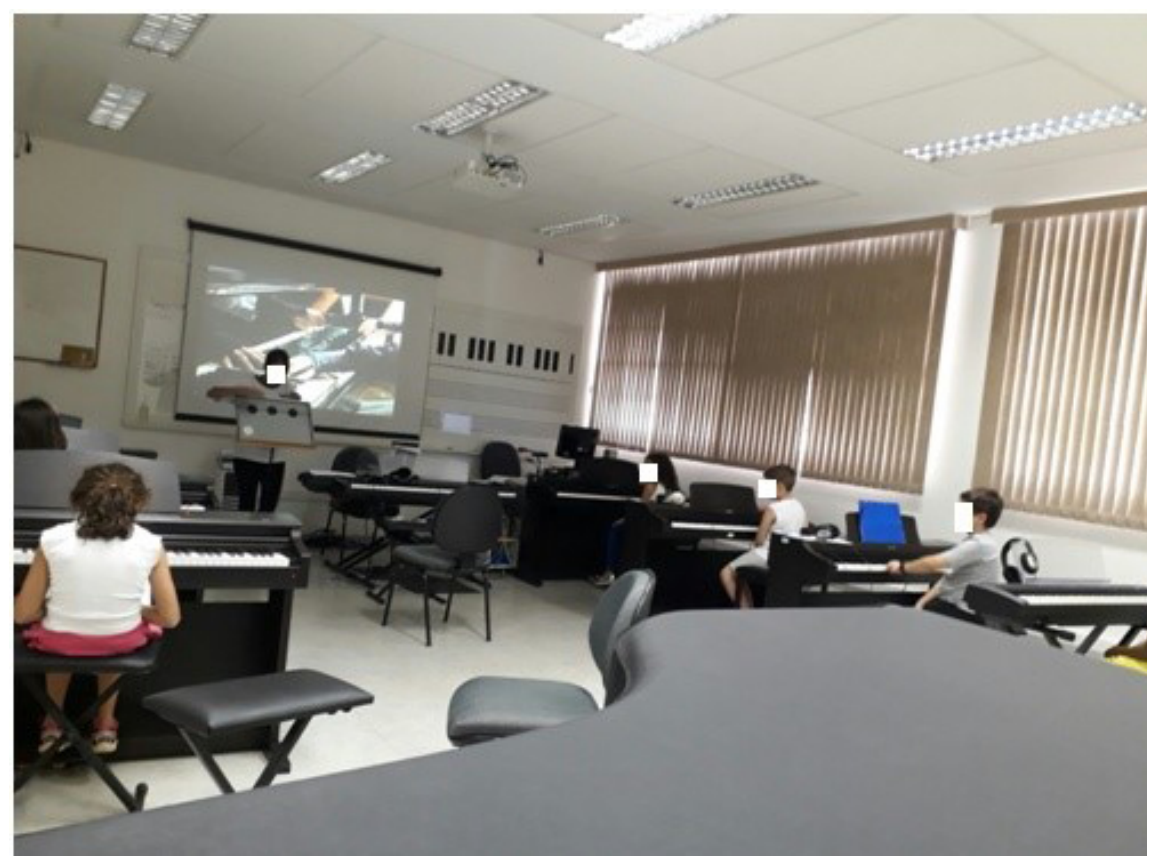

Figura 1: Piano em grupo em formato de laboratório no LabPC. 


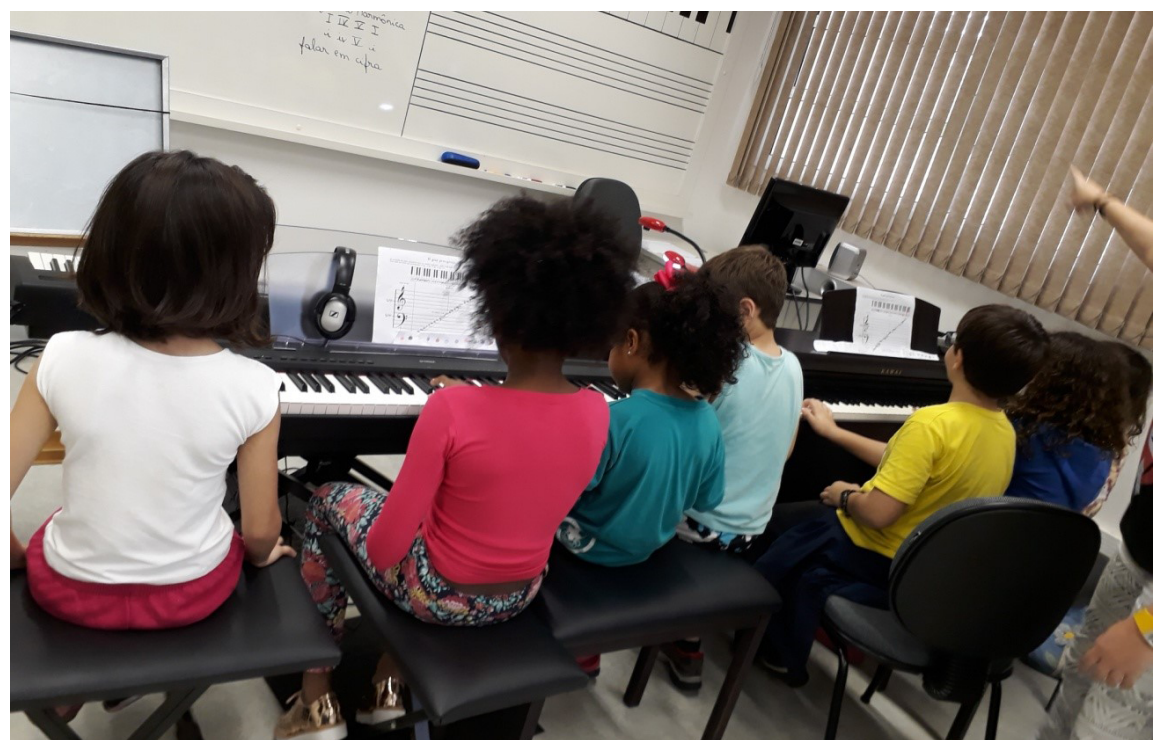

Figura 2: Piano em grupo com dois pianos e oito crianças no LabPG.

Buscamos proporcionar uma experiência que fosse permanente na vida de cada criança. Brandão (20|4, p. 14) afirma:

Devemos estar sempre preocupados em praticar uma educação cujo sentido seja o de recriar continuamente verdadeiras comunidades aprendentes, unidades dentro e fora das salas de aulas, geradoras de saberes e, de maneira crescente e sem limites, abertas ao diálogo e à intercomunicação.

\section{Estrutura da aula e material de apoio}

As aulas foram divididas em dez encontros, com duração de uma hora por semana cada. $\bigcirc$ conteúdo programático ficou organizado pelos seguintes tópicos:

- Abordagem dos mecanismos do piano (explicado em um piano de cauda); exploração ao teclado; postura/consciência corporal; diferenciação das alturas graves e agudas; disposição das teclas do piano; criação em teclas pretas; 
- dedilhado; leitura relativa; ritmo;

- pentagrama;

- figuras; fórmula de compasso;

- dinâmica;

- pausas;

- análise estrutural de uma peça (pergunta e resposta, padrões de ritmo e notas etc.);

- peça em conjunto;

- músicas tiradas "de ouvido".

Tivemos o lúdico como ferramenta principal das atividades desenvolvidas. Todas elas tiveram o princípio de ser um jogo ou uma brincadeira musical. Inclusive, buscamos trabalhar questões de outras disciplinas nas aulas, como a duração das figuras rítmicas por meio de subtração e somatória dos valores das figuras (associação da música com a matemática). Percebemos que as crianças conectavam, muitas vezes, o que foi aprendido em uma prática escolar, por exemplo, com o que estavam aprendendo na oficina.

As aulas tiveram como base as metodologias de Irina Corin e de Robert Pace. Os livros adotados foram Contos de uma jornada musical: para pequenos pianistas, seus professores e pais, de Irina Corin (2014), e Música para piano, de Robert Pace (1973). $\bigcirc$ livro de Irina Corin foi adotado por Bianca Viana Monteiro da Silva, e o livro de Pace por Ciulia Salgado Coelho da Silva. Os alunos tinham, então, 30 minutos de aula sobre a abordagem de Irina Corin, seguidos de 30 minutos da abordagem de Robert Pace.

A proposta do livro de Irina Corin (op. cit.) foi ao encontro do que foi idealizado: é uma obra que introduz e desenvolve conceitos musicais de maneira lúdica. Ademais, Gorin aborda as habilidades técnicas fundamentais e necessárias para o ensino de piano de maneira lúdica, a fim de conscientizar sobre "relaxamento e flexibilidade de toda a parte superior do corpo: ombros, braços, punhos e dedos" (lbid., p. 2). 
livro, apesar de ser composto para o ensino de piano individual, foi adequado para o ensino coletivo de piano. Me apropriei das atividades e orientações de ensino sobre os conceitos musicais. $\bigcirc$ material também inclui um CD, que foi utilizado nas aulas; ele contém os acompanhamentos harmônicos dos exercícios.

Vê-se, então, que a proposta de Corin é diferenciada, por abranger aspectos propícios para as aulas de piano em grupo: aborda aspectos teóricos musicais vinculados à prática de tocar piano. As atividades são expostas de forma paulatina, a fim de construir uma formação musical sólida. Ademais, há a preocupação com o preparo da postura e da conscientização corporal, e a questão da técnica é trabalhada de forma lúdica. Consideramos importante trabalhar esse quesito desde o primeiro contato com o piano. Apesar de questões intrinsecamente pianísticas não serem o principal foco da aula, achamos válido oferecer uma prática que abordasse a consciência postural (e, consequentemente, consciência corporal) desde o primeiro momento.

Para facilitar a compreensão de quem aplica o seu material, Corin formulou o livro Contos de uma jornada musical: guia para professores de piano, a fim de auxiliar os professores no entendimento das propostas.

livro Música para piano, de Robert Pace (1973) foi adotado por Giulia Salgado Coelho da Silva. A escolha dessa obra foi feita pelo fato de Pace ser um dos precursores do ensino de piano em grupo no Brasil, e o seu material foi planejado em formato de aula coletiva. Contudo, Giulia proporcionou aos alunos da Oficina de Piano em Grupo uma proposta mais lúdica, com brincadeiras e jogos (não é um quesito abordado nos livros de Pace).

\section{Considerações finais}

A realização da oficina foi considerada estimável. Tivemos relatos das crianças e dos pais sobre resultados positivos que a Oficina de Piano em Grupo proporcionou. Foi um espaço de vivencia musical bastante lúdico, que ofereceu às crianças e a nós, realizadores da oficina, uma experiência significativa. Como Bondía (2002, p. 26) afirma: 
"o saber de experiência se dá na relação entre o conhecimento e a vida humana". E, partindo desse olhar mais humanizado, trabalhamos na convivência e na colaboração mútua entre nós e os alunos, na qual todos agiram para um mesmo processo educativo, "sem hierarquias, em busca de ações cotidianas de reflexão e ação, nas quais o aprender e o ensinar são sempre caminhos de muitas mãos, nos quais todos se beneficiam" (JOLY et al., 2014, p. 240).

Acrescento que a oportunidade de "musicalizar" por meio do piano em uma prática em conjunto foi muito eficaz. Além das habilidades funcionais (como criação, leitura, treinamento auditivo, musicalidade, entre outras), foi um momento oportuno para desenvolver habilidades sociais, prática colaborativa, trabalho em equipe, dinâmica, aprendizado motivacional, entre outros benefícios.

Ademais, a instrução da profa. dra. Simone Corete Machado nos deu subsídios para darmos uma melhor aula de piano em grupo. Ela nos orientou sobre o planejamento das aulas, a escolha dos materiais, como proceder com a dinâmica em uma aula em formato de piano em grupo, acompanhou as aulas e, após o término de cada uma, nos dava sugestões de como aprimorar determinada atividade.

A experiência de ministrar aulas de piano em formato de grupo definiu aspectos que são necessários para a condução de uma aula na modalidade de piano em grupo: é necessário ser dinâmico, enérgico, objetivo, com comandos claros e precisos - além de ser fundamental proporcionar atividades sempre lúdicas.

A oficina se encerrou em 2017, mas pretendemos oferecer às crianças da comunidade essa vivência novamente, dando continuidade ao trabalho já iniciado.

\section{Referências}

BRANDÃO, Carlos R. Perguntas, pesquisas. Para quem? Para quê? In: OLIVEIRA, Maria W:; SOUSA, Fabiana R. (Orgs.). Processos educativos em práticas sociais: pesquisas em educação. São Carlos: EdUFSCar, 2014. p. $11-18$. 
FISHER, Christopher. Teaching piano in groups. Cary: Oxford University Press, 2010.

GORIN, Irina. Contos de uma jornada musical l: para pequenos pianistas, seus professores e pais. [S. I.]: Edição da autora, 2014.

JOLY, Ilza Z. L. et al. Pesquisa e intervenção em música: uma perspectiva da educação musical ao longo da vida. In: OLIVEIRA, Maria Waldenez; SOUSA, Fabiana Rodrigues (Orgs.). Processos educativos em práticas sociais: pesquisas em educação. São Carlos: EdUFSCar, 2014. p. 239-262.

BONDÍA, Jorge L. Notas sobre a experiência e o saber de experiência. Trad. de João Wanderley Geraldi. Revista Brasileira de Educação, Campinas, n. 19, p. 20-28, jan./abr. 2002.

MACHADO, Simone C. A presença do piano em grupo em instituições de ensino superior no Brasil. Orfeu, Florianópolis, v. I, n I, p. 132-155, jan.jjun. 2016.

PACE, Robert. Piano lessons: private or group?. Keyboard Journal, [S. I.], v. 4, n. 2, 1978.

Music for piano. New York: Lee Roberts Music Publication, 1973.

SILVA, Petronilha B. C. Práticas sociais e processos educativos: da vida e do estudo até o grupo de pesquisa. In: OLIVEIRA, Maria W.; SOUSA, Fabiana R. (Orgs.). Processos educativos em práticas sociais: pesquisas em educação. São Carlos: EdUFSCar, 2014. p. 19-27.

\section{Sobre as autoras}

Bianca Viana Monteiro da Silva é mestranda do Programa de PósGraduação em Música, linha de pesquisa Música e educação: processos de criação, ensino e aprendizagem pela Escola de Comunicação e Artes 
da Universidade de São Paulo (ECA-USP). Graduada em Educação Artística com habilitação em Música pelo Departamento de Música da Faculdade de Filosofia, Ciências e Letras de Ribeirão Preto da USP (FFCLRP-USP). Menção honrosa foi conferida a ela por ter se destacado com a mais alta média de notas no curso. Na graduação foi monitora com bolsa do Programa de Estímulo de Graduação da turma de Piano em Grupo sob orientação da Profa. Dra. Simone Corete Machado e desenvolveu projetos sob sua orientação. Publicou e apresentou em congressos sobre o ensino de Piano em Grupo e tem interesse nas áreas de Educação Musical e Ensino Coletivo.

Simone Corete Machado possui Mestrado em Música (Piano) e Especialização a nivel de Mestrado em Performance pela The Hartt Schol - University of Hartford (EUA); Doutorado em Artes Musicais (Piano/Ceneral Education) pela University of Arizona (EUA). Atualmente é Professora Doutora do DM da FFCLRP-USP. Suas atividades incluem docência, pesquisa, extensão e performance, além da coordenação do Laboratório de Piano em Grupo. É co-autora de Piano em grupo: livro didático para ensino superior, autora do Estudo comparativo de livros didáticos norte-americanos para piano em grupo (Revista Ictus) e Class piano connections: A Brazil-U.S. group piano project (Clavier Companion). Criou o Encontro de Piano em Grupo USP-RP dando prosseguimento à organização, em 2012, do II Encontro Internacional de Piano em Grupo.

Recebido em 13/01/2018

Aprovado em 03/02/20 18 